Research Paper

\title{
Weekly versus triweekly cisplatin-based concurrent chemoradiotherapy for nasopharyngeal carcinoma: a systematic review and pooled analysis
}

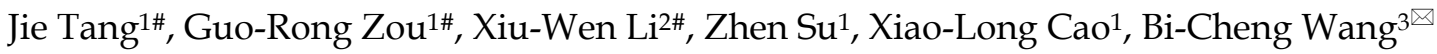 \\ 1. Department of Oncology, Panyu Central Hospital, Cancer Institute of Panyu, Guangzhou 511400, China. \\ 2. Department of Cardiology, Panyu Central Hospital, Guangzhou 511400, China. \\ 3. Cancer Center, Union Hospital, Tongji Medical College, Huazhong University of Science and Technology, Wuhan 430022, China. \\ \#These authors contributed equally to this study. \\ $\triangle$ Corresponding author: Bi-Cheng Wang, M.D., Cancer Center, Union Hospital, Tongji Medical College, Huazhong University of Science and Technology, 1277 Jiefang \\ Avenue, Wuhan 430022, China. Tel: +86 18995535334; E-mail: bcsnowell@163.com. \\ (C) The author(s). This is an open access article distributed under the terms of the Creative Commons Attribution License (https://creativecommons.org/licenses/by/4.0/). \\ See http://ivyspring.com/terms for full terms and conditions.
}

Received: 2021.04.30; Accepted: 2021.08.15; Published: 2021.08.28

\begin{abstract}
Background: Weekly and triweekly cisplatin-based concurrent chemoradiotherapy (CCRT) have been used in the treatment of nasopharyngeal carcinoma (NPC).

Objective: This study aimed to compare the benefits and risks between the two treatments.

Methods: We systematically searched electronic databases for prospective and retrospective clinical studies of NPC patients who received weekly compared with triweekly cisplatin-based CCRT. The primary endpoints comprised overall, failure-free, distant metastasis-free, and locoregional recurrence-free survivals (OS, FFS, DMFS, and LRFS). Secondary endpoints were toxicities.

Results: Six studies were included in the systematic review, of which four with 1515 NPC patients were eligible for further pooled analysis. There were no significant differences between weekly and triweekly groups in terms of 5-year OS (odds ratio [OR] 0.95, 95\% confidence interval [Cl] 0.51-1.79), FFS (OR 1.09, 95\% Cl $0.67-1.76$ ), DMFS (OR $1.25,95 \% \mathrm{Cl} 0.54-2.92$ ), and LRFS (OR $0.83,95 \% \mathrm{Cl} 0.55-1.25$ ). For grade $\geq 3$ toxicities, the weekly group had higher risks of anemia (risk ratio [RR] 2.96, 95\% $\mathrm{Cl} 1.12-7.81$ ) and thrombocytopenia (RR $2.75,95 \% \mathrm{Cl} 1.54-4.90)$, but a lower incidence of vomiting ( $R R 0.34,95 \% \mathrm{Cl} 0.18-0.63$ ) versus the triweekly group.

Conclusion and Relevance: Both weekly and triweekly schedules could be recommended to NPC patients during CCRT. Additionally, hematologic adverse events in weekly strategy and non-hematologic adverse events in triweekly strategy are of higher concern.
\end{abstract}

Key words: weekly; triweekly; cisplatin; concurrent chemotherapy; nasopharyngeal carcinoma

\section{Introduction}

In head and neck cancer (HNC), cisplatin-based concurrent chemotherapy (CCRT) is the standard of care. Previously reported meta-analyses showed that the effects of weekly cisplatin CCRT were comparable to triweekly strategy in treating head and neck cancers $[1,2]$. Subsequently, a randomized phase III trial indicated that triweekly cisplatin was superior to weekly cisplatin in improving locoregional recurrence-free survival (LRFS) [3]. Nevertheless, nasopharyngeal carcinoma (NPC) was excluded in these studies.
For patients with locoregionally advanced NPC, the mainstay of therapy is cisplatin-based CCRT as well. However, the 5-year overall survival rates vary from $67.9 \%$ to $80.2 \%$ when NPC patients receive weekly or triweekly cisplatin-based CCRT [4-7]. After reviewing the latest National Comprehensive Cancer Network (NCCN) guidelines on NPC, whether weekly or triweekly administration of cisplatin is recommended has not been clearly clarified [8]. According to the cited clinical trials, both strategies are reasonable treatments [9-11]. 
There is no solid evidence demonstrating the comparable survival outcomes of these two treatments for NPC. Consequently, we conducted this study to synthesize the published results in order to systematically review and pool-analyze the benefits and risks between weekly and triweekly cisplatinbased CCRT in NPC.

\section{Methods}

We conducted this study following the Preferred Reporting Items for Systematic Reviews and Meta-analyses (PRISMA) guideline [12].

\section{Search strategy and study selection}

The systemic search was done in PubMed, Web of Science, EMBASE, and Cochrane Library using the terms "nasopharyngeal", "carcinoma or cancer or tumor", "week or weekly", "three weeks or 3 weeks or 3-weekly or 3 weekly or three weekly or three-weekly or triweekly", "cisplatin", and "trial or study". The references of relevant published studies were manually searched for further eligible studies. The search was completed up to Dec 13, 2020. Subsequently, the searching process was conducted again on Jun 15, 2021 for updating the newly published records. Moreover, we expanded the literature search to PubMed Central from inception to Jun 15, 2021, which might carry the largest collection of free-full text medical articles among existing databases, and 3443 records were found. Since these records could not be uploaded to the EndNote software, two authors (Jie Tang and Bi-Cheng Wang) screened them carefully, but no more articles were additionally added to this study. Thus, records in PubMed Central database were not displayed in Figure 1.

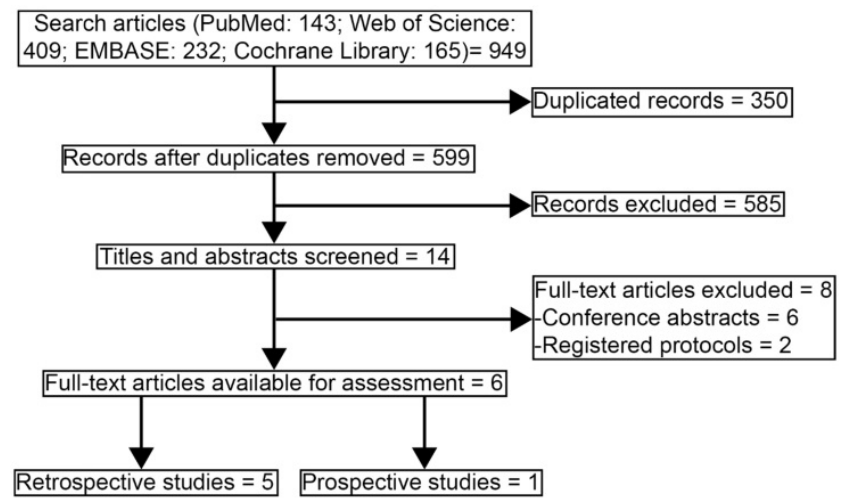

Figure 1. Study selecting process.

Studies eligible for inclusion met all of the following criteria: (1) previously untreated and non-distant metastatic patients with NPC, (2) participants were treated with weekly cisplatin-based
CCRT versus triweekly cisplatin-based CCRT, (3) prospective or retrospective studies were eligible, (4) data of survival outcomes and safety profiles were available, (5) published language was English. Conference abstracts were excluded. Any discrepancies were resolved by discussion.

\section{Quality assessment}

Since only retrospective studies were included in the meta-analysis, the nine-star Newcastle-Ottawa Scale was used to evaluate the quality [13]. Scores 7-9 points were defined as high quality, while scores $\leq 6$ were as low quality.

\section{Data extraction}

Basic characteristics concerning first author's name, publication year, study design, number of patients, cisplatin dosage, radiotherapy technology, induction or adjuvant chemotherapy regimens were collected. Data of primary endpoints (OS, failure-free survival [FFS, defined as the time from the date of randomization to the date of locoregional failure, distant failure, or death from any cause, whichever occurred first], distant metastasis-free [DMFS, defined as the time from documented distant metastasis or death from any cause], and LRFS [defined as the time from documented locoregional recurrence or death from any cause]) and secondary endpoints (safety profiles) were collected.

\section{Statistical analysis}

All analyses were done using STATA 14.0 software. $p<0.05$ was considered statistically significant. The survival data were assessed by odds ratios (ORs) and 95\% confidence interval (CI). Alternatively, the safety data were evaluated by risk ratios (RRs) and 95\% CI. Heterogeneity among the studies was calculated by using the $\chi^{2}$ tests. We also quantified the heterogeneity of the results using $I^{2}$ statistic percentages. A fixed-effects model (MantelHaenszel method) was applied if heterogeneity test showed no statistical significance $\left(I^{2} \leq 50 \%\right.$ or $\left.p \geq 0.10\right)$. Otherwise, a random-effects model was adopted.

\section{Results}

\section{Search results}

Figure 1 showed the study selection process of articles that were eligible in the systematic review and pooled analysis according to PRISMA [12]. 949 records were collected for the initial evaluation. 350 duplicating records were excluded. After reviewing the titles and abstracts, we excluded 585 irrelevant topics. There were 14 studies remaining for further review. Eight studies were excluded as the publication types were conference abstracts $(n=6)$ or 
registered protocols $(n=2)$. Finally, six studies were selected in the systematic review [14-19]. Since one study lack survival data and one study was a prospective trial, the other four retrospective studies were eligible in the further pooled analysis, with high qualities assessed by Newcastle-Ottawa scale [16-19].

Basic characteristics of the eligible studies included in the systematic review and pooled analysis were showed in Table 1. One study was prospective phase II clinical trials and five were retrospective studies. 3-dimensional conformal radiotherapy (3D-CRT) had been used in two studies and intensity-modulated radiotherapy (IMRT) had been applied in all six studies. In weekly group and triweekly group, respectively, patients were treated with $30-40 \mathrm{mg} / \mathrm{m}^{2}$ and $80-100 \mathrm{mg} / \mathrm{m}^{2}$. Patients in two studies received cisplatin plus 5 -fluorouracil adjuvant chemotherapy, but these patients were not included in the meta-analysis. All patients did not receive any induction chemotherapy.

\section{Survival outcomes}

Survival data were available from four studies with 1515 patients (weekly: 481; triweekly: 1034). Forest plots showed that weekly cisplatin-based CCRT failed to significantly prolong the 5-year OS (OR 0.95, 95\% CI 0.51-1.79, $p=0.885$ ), FFS (OR 1.09, 95\% CI 0.67-1.76, $p=0.735$ ), DMFS (OR 1.25, 95\% CI $0.54-2.92, p=0.598$ ), and LRFS (OR 0.83, 95\% CI $0.55-1.25, p=0.366)$.

The 5-year rates of OS, FFS, DMFS, and LRFS in weekly group were, respectively, $88.4 \% \quad(95 \%$ CI 81.6-95.3) versus $90.1 \%$ (95\% CI 88.3-91.9), 83.2\% (95\% CI $76.5-89.9$ ) versus $82.1 \%$ (95\% CI 75.4-88.8), $92.0 \%$ (95\% CI 86.8-97.2) versus 91.1\% (95\% CI 87.5-94.6), and $93.1 \%$ (95\% CI 89.7-96.6) versus $93.6 \%$ (95\% CI 91.5-95.7) compared to triweekly group (Table 2).

\section{Grade $\geq 3$ toxicities}

For grade $\geq 3$ hematologic toxicities, weekly cisplatin-based CCRT significantly increased the risks of anemia (RR 2.96, 95\% CI 1.12-7.81, $p=0.001$ ), but not thrombocytopenia (RR 1.24, 95\% CI 0.96-1.61, $p=$ 0.096) and leucopenia (RR 2.75, 95\% CI 1.54-4.90, $p=$ 0.096) compared to triweekly cisplatin-based CCRT. In terms of grade $\geq 3$ non-hematologic toxicities, weekly strategy had a lower risk of vomiting (RR 0.34, 95\% CI 0.18-0.63, $p=0.001$ ) and similar incidences of nausea (RR 0.55, 95\% CI 0.17-1.79, $p=0.318$ ) and mucositis (RR 0.81, 95\% CI 0.55-1.20, $p=0.287$ ) versus triweekly strategy.

\section{Discussion}

In the treatment for NPC patients, it is unclear how to administer CCRT based on the current NCCN guidelines. According to this study, we found that no significant differences were shown in all 5-year survival outcomes between weekly and triweekly treatments. The only prospective phase II study provided similar 3-year results [14]. However, weekly regimen was associated with improved quality of life 3 weeks after treatment completion [14].

Since the efficacy of both dosing frequencies are similar, it is also important to consider the dosing of weekly or triweekly cisplatin.

\section{Weekly $30 \mathrm{mg} / \mathrm{m}^{2}$ versus $40 \mathrm{mg} / \mathrm{m}^{2}$ cisplatin}

In our previous study [20], we found that most prospective randomized clinical trials utilized cisplatin $40 \mathrm{mg} / \mathrm{m}^{2}$ weekly. In patients treated with 40 $\mathrm{mg} / \mathrm{m}^{2}$ cisplatin based CCRT, the 3-year OS rates ranged from $71 \%$ to $92 \%$ and the 3-year FFS ranged from $57 \%$ to $67 \%$ [21-23]. Hong showed that NPC patients received $30 \mathrm{mg} / \mathrm{m}^{2}$ cisplatin had a 5 -year OS rate of $68 \%$ and a 5 -year FFS rate of $50 \%$ [4]. Based on these data, we cannot directly conclude whether 30 $\mathrm{mg} / \mathrm{m}^{2}$ or $40 \mathrm{mg} / \mathrm{m}^{2}$ has more favorable outcomes for NPC. After careful reading the details, we noticed that the compliance to concurrent cisplatin was a key obstacle because of nausea, vomiting, or hematological toxicities. In Fountzilas's study, no more than $75 \%$ of enrolled NPC patients received a cumulative dose of over $200 \mathrm{mg} / \mathrm{m}^{2}$ cisplatin [21]. $16 \%$ of patients in the CCRT alone group in Tan's research had cisplatin discontinued eventually. In Frikha's study, only $22 \%$ patients in the CCRT group could receive the full dose of concurrent cisplatin [23]. However, for NPC patients in Hong's clinical trial, there were 233 of 240 patients completing the 30 $\mathrm{mg} / \mathrm{m}^{2}$ cisplatin-based CCRT, with greatly higher treatment compliance than $40 \mathrm{mg} / \mathrm{m}^{2}$ cisplatin [4]. Based on current clinical practice, we suggest that 30 $\mathrm{mg} / \mathrm{m}^{2}$ cisplatin with at least six cycles could be a feasible concurrent strategy due to a better tolerability over $40 \mathrm{mg} / \mathrm{m}^{2} /$ week.

Triweekly $80 \mathrm{mg} / \mathrm{m}^{2}$ versus $100 \mathrm{mg} / \mathrm{m}^{2}$ cisplatin: In Zhang's study, $98 \%$ of patients completed at least two cycles of $100 \mathrm{mg} / \mathrm{m}^{2}$ cisplatin-based CCRT [9]. The 3-year OS and FFS rates in CCRT group were $85 \%$ and $74 \%$. Sun and colleagues reported a 99\% rate of patients given CCRT alone in finishing at least two cycles of $100 \mathrm{mg} / \mathrm{m}^{2}$ cisplatin during CCRT, with $82 \%$ (3-year OS), 77\% (5-year OS), 70\% (3-year FFS), and 63\% (5-year FFS) of survival rates [5, 24]. Among patients treated with $80 \mathrm{mg} / \mathrm{m}^{2}$ cisplatin-based CCRT alone in Cao's study, $96.8 \%$ of participants completed at least two cycles of concomitant cisplatin chemotherapy $[6,25]$. The 3 -year rates of OS and FFS were $88 \%$ and $74 \%$, while the 5 -year rates were $77 \%$ and $63 \%$. Accordingly, both 
$80 \mathrm{mg} / \mathrm{m}^{2}$ and $100 \mathrm{mg} / \mathrm{m}^{2}$ cisplatin-based CCRT have highly treatment compliances. There were no obvious differences in survival responses between the two groups. Therefore, it is possible that a cumulative dose of $160 \mathrm{mg} / \mathrm{m}^{2}$ cisplatin may be sufficient for CCRT, compared to $200 \mathrm{mg} / \mathrm{m}^{2}$.

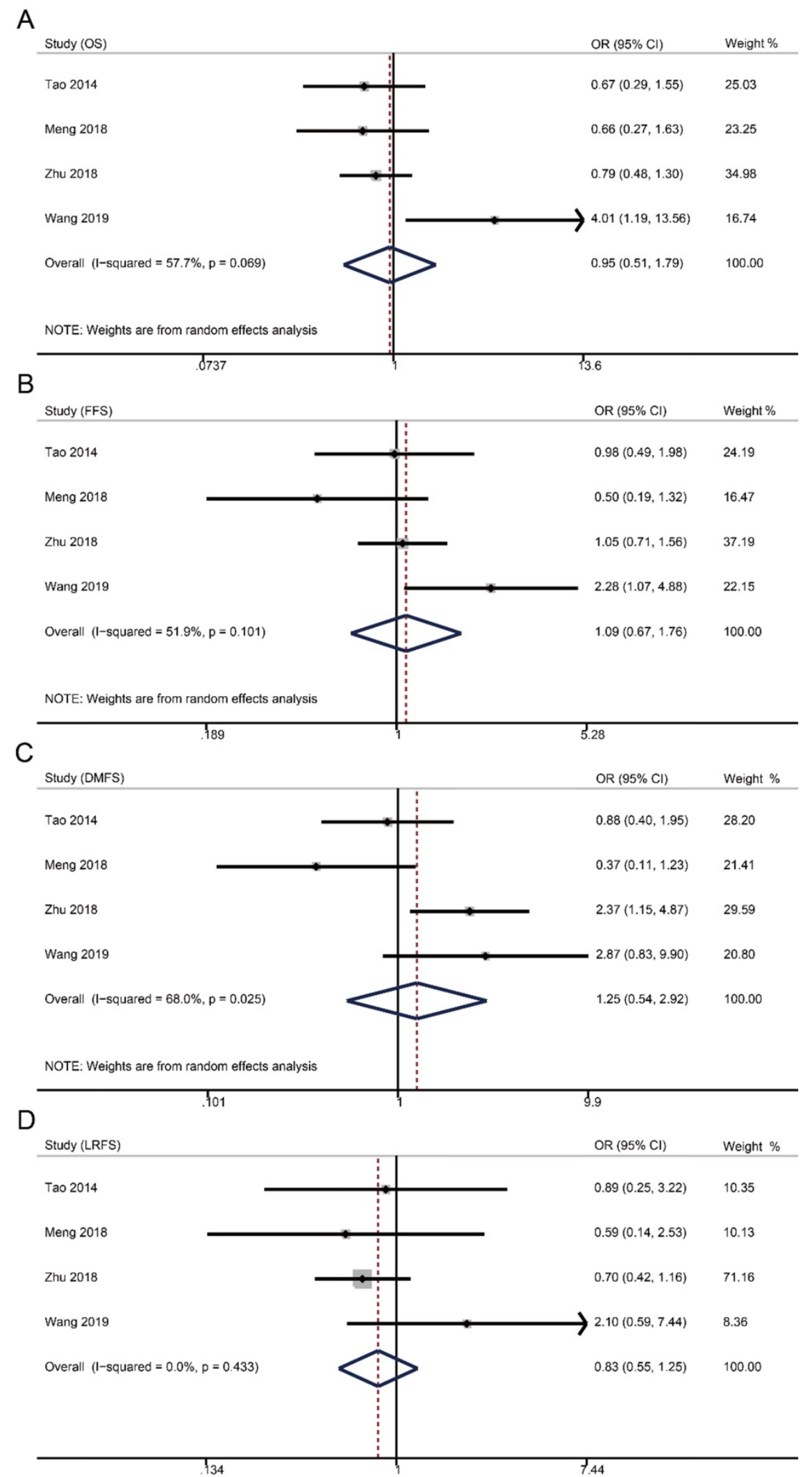

Figure 2. Forest plots of 5-year survival outcomes for weekly versus triweekly cisplatin-based CCRT. (A) overall survival; (B) failure-free survival; (C) distant metastasisfree survival; (D) locoregional recurrence-free survival. OR, odds ratio. 
Table 1. Basic characteristics of the selected studies in the systemic review

\begin{tabular}{|c|c|c|c|c|c|c|c|c|c|c|c|}
\hline Study & Year & Design & Groups & $\begin{array}{l}\text { No. } \\
\text { patients }\end{array}$ & Stage & AJCC/UICC & Dosage & Radiotherapy & $\begin{array}{l}\text { Induction } \\
\text { chemotherapy }\end{array}$ & $\begin{array}{l}\text { Adjuvant } \\
\text { chemotherapy }\end{array}$ & $\begin{array}{l}\text { NOS } \\
\text { scores }\end{array}$ \\
\hline Lee & 2016 & Prospective & $\begin{array}{l}\text { Weekly } \\
\text { Trweekly }\end{array}$ & $\begin{array}{l}53 \\
56\end{array}$ & II-IVb & 5th & $\begin{array}{l}40 \mathrm{mg} / \mathrm{m}^{2} \\
100 \mathrm{mg} / \mathrm{m}^{2}\end{array}$ & 3D-CRT/IMRT & / & $\begin{array}{l}\text { Cisplatin and } \\
\text { 5-fluorouracil }\end{array}$ & / \\
\hline Jagdis & 2014 & Retrospective & $\begin{array}{l}\text { Weekly } \\
\text { Trweekly }\end{array}$ & $\begin{array}{l}45 \\
28\end{array}$ & II-IVb & 7 th & $\begin{array}{l}40 \mathrm{mg} / \mathrm{m}^{2} \\
100 \mathrm{mg} / \mathrm{m}^{2}\end{array}$ & 3D-CRT/IMRT & / & $\begin{array}{l}\text { Cisplatin and } \\
\text { 5-fluorouracil }\end{array}$ & / \\
\hline Tao & 2014 & Retrospective & $\begin{array}{l}\text { Weekly } \\
\text { Trweekly }\end{array}$ & $\begin{array}{l}73 \\
81\end{array}$ & II-IVb & 7 th & $\begin{array}{l}40 \mathrm{mg} / \mathrm{m}^{2} \\
80 \mathrm{mg} / \mathrm{m}^{2}\end{array}$ & IMRT & / & / & 9 \\
\hline Meng & 2018 & Retrospective & $\begin{array}{l}\text { Weekly } \\
\text { Trweekly }\end{array}$ & $\begin{array}{l}90 \\
90\end{array}$ & III-IVb & 7 th & $\begin{array}{l}30-40 \mathrm{mg} / \mathrm{m}^{2} \\
80 \mathrm{mg} / \mathrm{m}^{2}\end{array}$ & IMRT & / & / & 9 \\
\hline Zhu & 2018 & Retrospective & $\begin{array}{l}\text { Weekly } \\
\text { Trweekly }\end{array}$ & $\begin{array}{l}225 \\
634\end{array}$ & III-IVb & 7 th & $\begin{array}{l}40 \mathrm{mg} / \mathrm{m}^{2} \\
100 \mathrm{mg} / \mathrm{m}^{2}\end{array}$ & IMRT & / & / & 9 \\
\hline Wang & 2019 & Retrospective & $\begin{array}{l}\text { Weekly } \\
\text { Trweekly }\end{array}$ & $\begin{array}{l}93 \\
229\end{array}$ & I-IVa & 8th & $\begin{array}{l}30-40 \mathrm{mg} / \mathrm{m}^{2} \\
80-100 \mathrm{mg} / \mathrm{m}^{2}\end{array}$ & IMRT & / & / & 9 \\
\hline
\end{tabular}

Abbreviations: AJCC, American Joint Commission on Cancer; UICC, Union for International Cancer Control; 3D-CRT, 3-dimensional conformal radiotherapy; IMRT, intensity-modulated radiotherapy; NOS, Newcastle-Ottawa scale.

A

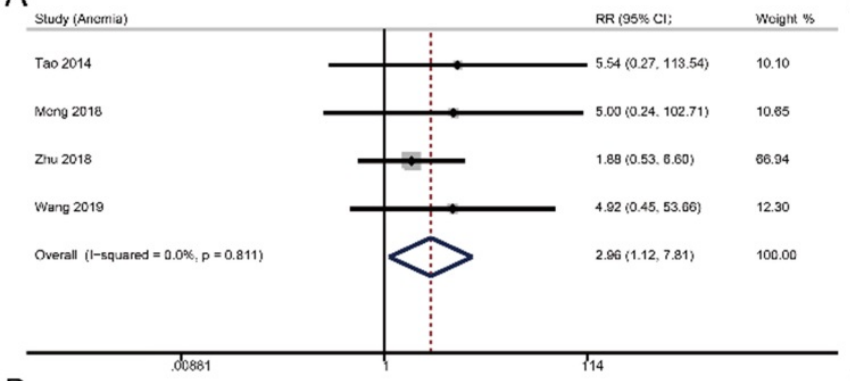

B

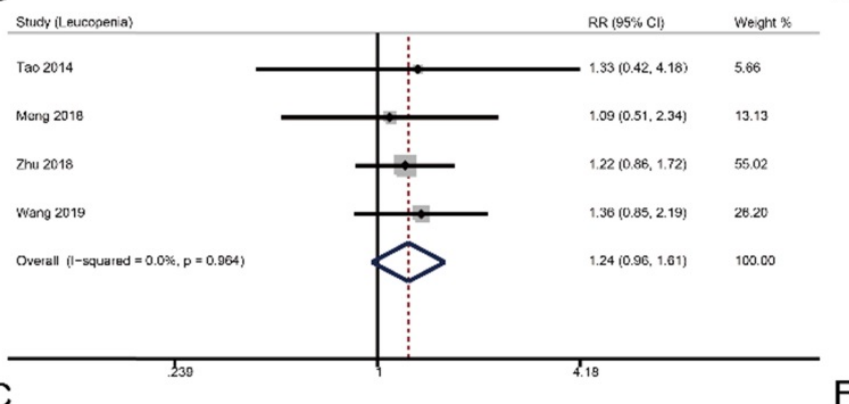

C

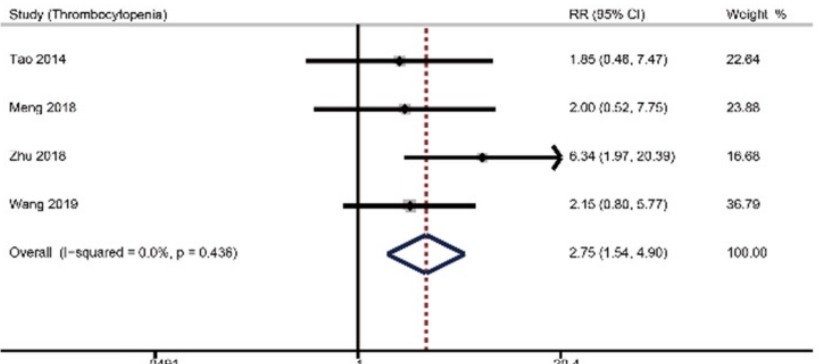

D

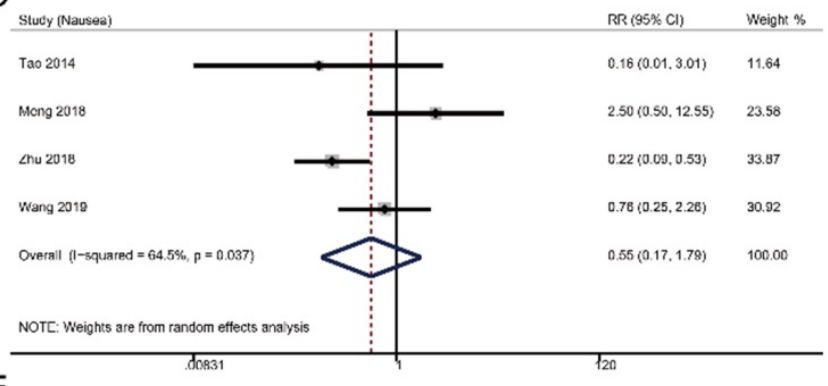

$\mathrm{E}$

Stucy \{ Nomitings

Tà 2014

Meng 2018

Zhu 2018

Wang 2019

Overal (1-squared $=16.3 \%, p=0.310$ )

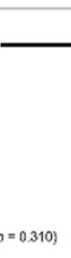

$R R(95 \% \mathrm{Cl})$ $0.16(0.01,3.01) \quad 7.25$ $0.67(0.11 .3 .90) \quad 6.55$ $0.23(0.08,0.57) \quad 69.78$ $0.76(0.25 .2 .26) \quad 16.40$ $0.34(0.18,0.63) \quad 100.00$

$\mathrm{F}$

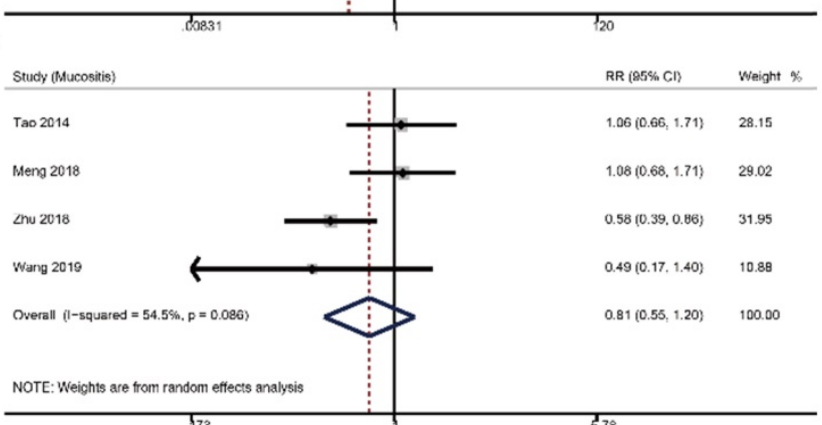

Figure 3. Forest plots of toxicities in comparing the weekly and triweekly cisplatin strategies during CCRT. (A) anemia; (B) leucopenia; (C) thrombocytopenia; (D) nausea; (E) vomiting; (F) mucositis. RR, risk ratio.

Table 2. Survival outcomes in the two groups

\begin{tabular}{lll}
\hline 5-year & \multicolumn{2}{l}{ Rate $\%, 95 \%$ CI } \\
\cline { 2 - 3 } responses & weekly & triweekly \\
\hline OS & $88.4,81.6-95.3$ & $90.1,88.3-91.9$ \\
FFS & $83.2,76.5-89.9$ & $82.1,75.4-88.8$ \\
DMFS & $92.0,86.8-97.2$ & $91.1,87.5-94.6$ \\
LRFS & $93.1,89.7-96.6$ & $93.6,91.5-95.7$ \\
\hline Abbreviations: OS, overall survival; FFS, failure-free survival; DMFS: distant \\
metastasis-free survival; LRFS: locoregional recurrence-free survival; 95\% CI, 95\% \\
confidence interval.
\end{tabular}

In clinical practice, if total dose of cisplatin during CCRT is set to $200 \mathrm{mg} / \mathrm{m}^{2}$, triweekly 100 $\mathrm{mg} / \mathrm{m}^{2}$ cisplatin might be a better choice. Alternatively, if the total dose is $160 \mathrm{mg} / \mathrm{m}^{2}$, we consider that triweekly $80 \mathrm{mg} / \mathrm{m}^{2}$ with two cycles is reasonable. However, the mainly reasons for discontinuation were adverse events. 


\section{Toxicities}

We choose six grade $\geq 3$ adverse events in analyzing the risks, including anemia, leucopenia, thrombocytopenia, nausea, vomiting, and mucositis, because the data of these toxicities were available from the four studies [16-19]. Although we noticed that there were significant differences in anemia and vomiting, the incidences were low and these adverse events could be well managed. Nevertheless, the eligible studies were retrospective researches and did not fully provide the safety profiles. Actually, NPC patients should receive adequate symptomatic supportive care during CCRT to ensure the continuation of cisplatin-based treatments.

Another issue is whether or not concurrent cisplatin schedules will affect survival and toxicity in already chemotherapy-loaded patients, compared to chemotherapy naïve patients. For locoregionally advanced NPC patients, mounts of large-scale prospective clinical trials have demonstrated that induction chemotherapy followed by CCRT is the standard of care $[4,6,9,21,26-30]$. In a previously published analysis, seven trials were enrolled, with four trials adopting weekly cisplatin schedule and the other three trials adopting triweekly cisplatin schedule [20]. Additionally, CCRT plus adjuvant chemotherapy could also be a therapeutic strategy for NPC patients $[7,31]$. In these studies, both weekly and triweekly strategies were used. However, there is still a lack of head-to-head clinical trials to certify the impacts of different cisplatin-based CCRT schedules on survival outcomes and toxicities in patients who are prescribed to receive induction or adjuvant chemotherapy. Based on our results, both treatments were feasible, which might shed some light and provide possible direction to designing future clinical trials.

\section{Limitations}

There were several limitations that might increase the risk of bias of this meta-analysis. (1) The four eligible studies in pooled analysis were retrospective clinical researches; (2) the weekly cisplatin schedule included $30 \mathrm{mg} / \mathrm{m}^{2}$ and $40 \mathrm{mg} / \mathrm{m}^{2}$ and the triweekly cisplatin schedule comprised 80 $\mathrm{mg} / \mathrm{m}^{2}$ and $100 \mathrm{mg} / \mathrm{m}^{2}$; (3) only three types of hematologic toxicities (grade $\geq 3$ anemia, leucopenia, and thrombocytopenia) and three types of nonhematologic toxicities (grade $\geq 3$ nausea, vomiting, and mucositis) were analyzed. In addition, data of nausea and vomiting in Tao's and Wang' studies could not be clearly separated.

\section{Conclusion and Relevance}

Either weekly or triweekly cisplatin during
CCRT could be an option for the treatment of NPC. More prospective clinical trials are warranted to confirm our results.

\section{Acknowledgements}

We would like to thank other colleagues in the oncology department of Panyu central hospital.

\section{Funding}

This study was supported by the Hubei Provincial Natural Science Foundation (Grant number: 2020CFB397 to Bi-Cheng Wang) and the Independent Innovation Foundation of Wuhan Union Hospital (Grant number: 2019-109 to Bi-Cheng Wang).

\section{Authors' Note}

Study design: Bi-Cheng Wang and Jie Tang; Data extraction: Bi-Cheng Wang, Jie Tang, Guo-Rong Zou, Xiu-Wen Li, Zen Su, and Xiao-Long Cao; Data analysis: Bi-Cheng Wang, Jie Tang, Guo-Rong Zou, and Xiu-Wen Li; Manuscript writing: Bi-Cheng Wang, Jie Tang; Manuscript edition: Bi-Cheng Wang, and Jie Tang. All authors have read and approved the manuscript.

\section{ORCID ID}

Bi-Cheng Wang: https://orcid.org/0000-00024598-7721.

\section{Competing Interests}

The authors have declared that no competing interest exists.

\section{References}

1. Szturz P, Wouters K, Kiyota N, Tahara M, Prabhash K, Noronha V, et al. Weekly Low-Dose Versus Three-Weekly High-Dose Cisplatin for Concurrent Chemoradiation in Locoregionally Advanced Non-Nasopharyngeal Head and Neck Cancer: A Systematic Review and Meta-Analysis of Aggregate Data. Oncologist. 2017; 22: 1056-66.

2. Jacinto JK, Co J, Mejia MB, Regala EE. The evidence on effectiveness of weekly vs triweekly cisplatin concurrent with radiotherapy in locally advanced head and neck squamous cell carcinoma (HNSCC): a systematic review and meta-analysis. Br J Radiol. 2017; 90: 20170442.

3. Noronha V, Joshi A, Patil VM, Agarwal J, Ghosh-Laskar S, Budrukkar A, et al. Once-a-Week Versus Once-Every-3-Weeks Cisplatin Chemoradiation for Locally Advanced Head and Neck Cancer: A Phase III Randomized Noninferiority Trial. J Clin Oncol. 2018; 36: 1064-72.

4. Hong RL, Hsiao CF, Ting LL, Ko JY, Wang CW, Chang JTC, et al. Final results of a randomized phase III trial of induction chemotherapy followed by concurrent chemoradiotherapy versus concurrent chemoradiotherapy alone in patients with stage IVA and IVB nasopharyngeal carcinoma-Taiwan Cooperative Oncology Group (TCOG) 1303 Study. Ann Oncol. 2018; 29: 1972-9.

5. Sun $\mathrm{Y}, \mathrm{Li}$ WF, Chen NY, Zhang $\mathrm{N}, \mathrm{Hu} \mathrm{GQ}$ Xie FY, et al. Induction chemotherapy plus concurrent chemoradiotherapy versus concurrent chemoradiotherapy alone in locoregionally advanced nasopharyngeal carcinoma: a phase 3, multicentre, randomised controlled trial. Lancet Oncol. 2016; 17: 1509-20.

6. Cao SM, Yang Q, Guo L, Mai HQ, Mo HY, Cao KJ, et al. Neoadjuvant chemotherapy followed by concurrent chemoradiotherapy versus concurrent chemoradiotherapy alone in locoregionally advanced nasopharyngeal carcinoma: A phase III multicentre randomised controlled trial. Eur J Cancer. 2017; 75: 14-23.

7. Chen L, Hu CS, Chen XZ, Hu GQ, Cheng ZB, Sun Y, et al. Concurrent chemoradiotherapy plus adjuvant chemotherapy versus concurrent chemoradiotherapy alone in patients with locoregionally advanced 
nasopharyngeal carcinoma: a phase 3 multicentre randomised controlled trial. The Lancet Oncology. 2012; 13: 163-71.

8. National Comprehensive Cancer Network. Head and Neck Cancers (Version 1, 2020). 2020.

9. Zhang Y, Chen L, Hu GQ, Zhang N, Zhu XD, Yang KY, et al. Gemcitabine and Cisplatin Induction Chemotherapy in Nasopharyngeal Carcinoma. N Engl J Med. 2019; 381: 1124-35.

10. Al-Sarraf M, LeBlanc M, Giri PG, Fu KK, Cooper J, Vuong T, et al. Chemoradiotherapy versus radiotherapy in patients with advanced nasopharyngeal cancer: phase III randomized Intergroup study 0099. J Clin Oncol. 1998; 16: 1310-7.

11. Chan AT, Leung SF, Ngan RK, Teo PM, Lau WH, Kwan WH, et al. Overall survival after concurrent cisplatin-radiotherapy compared with radiotherapy alone in locoregionally advanced nasopharyngeal carcinoma. J Natl Cancer Inst. 2005; 97: 536-9.

12. Stewart LA, Clarke M, Rovers M, Riley RD, Simmonds M, Stewart G, et al. Preferred Reporting Items for Systematic Review and Meta-Analyses of individual participant data: the PRISMA-IPD Statement. Jama. 2015; 313: 1657-65.

13. Wells GA SB, O'Connell D, Peterson J, Welch V, Losos M, Tugwell P,. The Newcastle-Ottawa Scale (NOS) for assessing the quality of nonrandomised studies http://www.ohri.ca/programs/clinical_epidemiology/oxford.asp.

14. Lee JY, Sun J-M, Oh DR, Lim SH, Goo J, Lee S-H, et al. Comparison of weekly versus triweekly cisplatin delivered concurrently with radiation therapy in patients with locally advanced nasopharyngeal cancer: A multicenter randomized phase II trial (KCSG-HN10-02). Radiotherapy and Oncology. 2016; 118: 244-50.

15. Jagdis A, Laskin J, Hao D, Hay J, Wu J, Ho C. Dose Delivery Analysis of Weekly Versus 3-Weekly Cisplatin Concurrent With Radiation Therapy for Locally Advanced Nasopharyngeal Carcinoma (NPC). American Journal of Clinical Oncology-Cancer Clinical Trials. 2014; 37: 63-9.

16. Tao C-J, Lin L, Zhou G-Q, Tang L-L, Chen L, Mao Y-P, et al. Comparison of Long-Term Survival and Toxicity of Cisplatin Delivered Weekly versus Every Three Weeks Concurrently with Intensity-Modulated Radiotherapy in Nasopharyngeal Carcinoma. Plos One. 2014; 9: e110765.

17. Meng D-F, Sun R, Peng L-X, Huang Y-S, Yang Q, Luo D-H, et al. A comparison of weekly versus 3-weekly cisplatin during concurrent chemoradiotherapy for locoregionally advanced nasopharyngeal carcinoma using intensity modulated radiation therapy: a matched study. Journal of Cancer. 2018; 9: 92-9.

18. Zhu Q, Hu H, Tang L-Q, You R, Zhao J-J, Weng D-S, et al. Weekly versus triweekly cisplatin plus intensity-modulated radiotherapy in locally advanced nasopharyngeal carcinoma: A propensity score analysis with a large cohort. Journal of Cancer. 2018; 9: 3447-55.

19. Wang K, Dong J, He S, Wang X, Jiang C, Hu P, et al. Comparison of weekly and triweekly cisplatin regimens during concurrent chemoradiotherapy for nasopharyngeal carcinoma. Bmc Cancer. 2019; 19(1): 482.

20. Wang BC, Xiao BY, Lin GH, Wang C, Liu Q. The efficacy and safety of induction chemotherapy combined with concurrent chemoradiotherapy versus concurrent chemoradiotherapy alone in nasopharyngeal carcinoma patients: a systematic review and meta-analysis. BMC Cancer. 2020; 20: 393.

21. Fountzilas G, Ciuleanu E, Bobos M, Kalogera-Fountzila A, Eleftheraki AG, Karayannopoulou G, et al. Induction chemotherapy followed by concomitant radiotherapy and weekly cisplatin versus the same concomitant chemoradiotherapy in patients with nasopharyngeal carcinoma: a randomized phase II study conducted by the Hellenic Cooperative Oncology Group (HeCOG) with biomarker evaluation. Ann Oncol. 2012; 23: 427-35.

22. Tan T, Lim WT, Fong KW, Cheah SL, Soong YL, Ang MK, et al. Concurrent chemo-radiation with or without induction gemcitabine, Carboplatin, and Paclitaxel: a randomized, phase $2 / 3$ trial in locally advanced nasopharyngeal carcinoma. Int J Radiat Oncol Biol Phys. 2015; 91: 952-60.

23. Frikha M, Auperin A, Tao Y, Elloumi F, Toumi N, Blanchard P, et al. A randomized trial of induction docetaxel-cisplatin-5FU followed by concomitant cisplatin-RT versus concomitant cisplatin-RT in nasopharyngeal carcinoma (GORTEC 2006-02). Ann Oncol. 2018; 29: 731-6.

24. Li WF, Chen NY, Zhang N, Hu GQ, Xie FY, Sun Y, et al. Concurrent chemoradiotherapy with/without induction chemotherapy in locoregionally advanced nasopharyngeal carcinoma: Long-term results of phase 3 randomized controlled trial. Int J Cancer. 2019; 145: 295-305.

25. Yang Q, Cao SM, Guo L, Hua YJ, Huang PY, Zhang XL, et al. Induction chemotherapy followed by concurrent chemoradiotherapy versus concurrent chemoradiotherapy alone in locoregionally advanced nasopharyngeal carcinoma: long-term results of a phase III multicentre randomised controlled trial. Eur J Cancer. 2019; 119: 87-96.

26. Tan T, Lim W-T, Fong K-W, Cheah S-L, Soong Y-L, Ang M-K, et al. Concurrent Chemo-Radiation With or Without Induction Gemcitabine, Carboplatin, and Paclitaxel: A Randomized, Phase 2/3 Trial in Locally Advanced Nasopharyngeal Carcinoma. International Journal of Radiation Oncology Biology Physics. 2015; 91: 952-60.

27. Li W-F, Chen N-Y, Zhang N, Hu G-Q, Xie F-Y, Sun Y, et al. Concurrent chemoradiotherapy with/without induction chemotherapy in locoregionally advanced nasopharyngeal carcinoma: Long-term results of phase 3 randomized controlled trial. International Journal of Cancer. 2019; 145: 295-305.
28. Yang Q, Cao S-M, Guo L, Hua Y-J, Huang P-Y, Zhang X-L, et al. Induction chemotherapy followed by concurrent chemoradiotherapy versus concurrent chemoradiotherapy alone in locoregionally advanced nasopharyngeal carcinoma: long-term results of a phase III multicentre randomised controlled trial. European journal of cancer (Oxford, England : 1990). 2019; 119: 87-96.

29. Sun $\mathrm{Y}, \mathrm{Li}$ W-F, Chen N-Y, Zhang N, Hu G-Q, Xie F-Y, et al. Induction chemotherapy plus concurrent chemoradiotherapy versus concurrent chemoradiotherapy alone in locoregionally advanced nasopharyngeal carcinoma: a phase 3, multicentre, randomised controlled trial. Lancet Oncology. 2016; 17: 1509-20.

30. Frikha M, Auperin A, Tao Y, Elloumi F, Toumi N, Blanchard P, et al. A randomized trial of induction docetaxel-cisplatin-5FU followed by concomitant cisplatin-RT versus concomitant cisplatin-RT in nasopharyngeal carcinoma (GORTEC 2006-02). Annals of Oncology. 2018; 29: 731-6.

31. Lee AWM, Tung SY, Ng WT, Lee V, Ngan RKC, Choi HCW, et al. A multicenter, phase 3 , randomized trial of concurrent chemoradiotherapy plus adjuvant chemotherapy versus radiotherapy alone in patients with regionally advanced nasopharyngeal carcinoma: 10-year outcomes for efficacy and toxicity. Cancer. 2017; 123: 4147-57. 